\title{
Feasibility of Sonography in estimating Fetal Weight of Low Birth Weight Babies
}

\author{
${ }^{1}$ Sanghamithra Reddy, ${ }^{2}$ Shripad Hebbar, ${ }^{3}$ Lavanya Rai
}

\begin{abstract}
Background: Currently available ultrasound-based fetal birth weight estimation methods have been designed for a group of neonates with wide birth weight range and hence are faced with increased error of margin. Whenever there is a need for delivering pregnant woman with small fetus, prior knowledge of approximate fetal weight is of utmost importance for neonatal survival, and an error in this process can result in significant morbidity/mortality to the newborn baby. This necessitates need for the establishment of new birth weight formula exclusively for this subset of fetuses.
\end{abstract}

Objectives: To test the accuracy of established formulae in fetuses $\leq 2000 \mathrm{gm}$ at birth in singleton pregnancies. To develop new formula for this group of small fetuses delivering in our institution with maximal accuracy and reliability and to prospectively validate this formula in subsequent set of pregnant cohort.

Materials and methods: The current study was done in two phases: The first phase was a formula derivation phase wherein the four major parameters [biparietal diameter (BPD), head circumference $(\mathrm{HC})$, abdominal circumference (AC), and femur length (FL)] were evaluated from a set of 128 postpartum women who delivered a neonate weighing $\leq 2 \mathrm{~kg}$ within 1 week of ultrasound examination. Stepwise regression analysis using birth weight as dependent parameter and fetal biometric parameters as independent parameters was used to develop the best formula for estimating fetal weight at birth. In the second phase (formula validation phase), the newly derived formula was tested for its accuracy in 31 pregnant women who gave birth to neonates weighing $\leq 2 \mathrm{~kg}$

Results: The new formula $(\log 10[\mathrm{BW}]=1.0131+0.0216 \times \mathrm{HC}+$ $0.0448 \times \mathrm{AC}+0.2183 \times \mathrm{FL}+0.0001 \times \mathrm{BPD} \times \mathrm{AC}-0.0059 \times \mathrm{AC} \times \mathrm{FL})$ was superior to established birth weight formulae. In the formula derivation group, the lowest mean \pm standard deviation (SD) absolute error was $130 \pm 91 \mathrm{gm}$ and the lowest mean absolute percentage error was $9.8 \pm 7 \%$ SD for the new formula and $61.7 \%$ of weight estimates fell within $\pm 10 \%$ of the actual weight at birth and this percentage further increased to 83.6 and $91.4 \%$ for error of margin of \pm 15 and $\pm 20 \%$ respectively. When this formula was applied in the validation group, the absolute error in grams was $102 \pm 115$ and absolute percentage error was $7.4 \pm 7$; hence

\footnotetext{
${ }^{1}$ Junior Resident, ${ }^{2}$ Professor, ${ }^{3}$ Professor and Head

${ }^{1-3}$ Department of Obstetrics and Gynecology, Kasturba Medical College, Manipal, Karnataka, India
}

Corresponding Author: Shripad Hebbar, Professor, Department of Obstetrics and Gynecology, Kasturba Medical College Manipal, Karnataka, India, Phone: +919886369753, e-mail: drshripadhebbar@yahoo.co.in
$77.4 \%$ fell within $10 \%, 80.6 \%$ fell within $15 \%$, $90.3 \%$ fell within $20 \%$. Further, in the validation group, mean \pm SD of estimated birth weight was $1337 \pm 406 \mathrm{gm}$, which was closest to actual birth weight (1328 $\pm 433 \mathrm{gm})$.

Conclusion: Our new formula is likely to estimate birth weight in small fetuses $(\leq 2 \mathrm{~kg}$ ) with reasonable accuracy and reliability. When compared to available methods of ultrasound birth weight estimation, absolute error and absolute percentage error is least with our formula indicating a good fit.

Keywords: Estimated fetal weight, Obstetric ultrasound, Smallfor-gestational age (SGA).

How to cite this article: Reddy S, Hebbar S, Rai L. Feasibility of Sonography in estimating Fetal Weight of Low Birth Weight Babies. Int J Infertil Fetal Med 2016;7(2):42-48.

\section{Source of support: Nil}

Conflict of interest: None

Date of received: 8-3-2016

Date of acceptance: 19-4-2016

Date of publication: August 2016

\section{INTRODUCTION}

Various fetal weight formulae available were first developed 20 to 30 years ago and were based on ultrasound examination of average-sized babies. With recent developments in neonatal medicine, even extremely small birth weight babies (weighing as less as $600 \mathrm{gm}$ ) stand a reasonably good chance of survival and a small error in estimating birth weight can greatly alter the prognosis. Perinatal morbidity and mortality are highest in lowest weight range, so the antenatal fetal weight estimation for the small fetus should be precise. Several studies have shown that generalized birth weight estimation methods perform poorly in predicting birth weights for smallfor-gestational age (SGA) fetutes. ${ }^{1,2}$ Though there are no definite reasons why these prediction models fail, one of the hypothesis is that these subsets of neonates have different body proportions compared to term babies. ${ }^{3}$ This may result in different weightage for traditionally obtained fetal biometric parameters, such as biparietal diameter (BPD), head circumference (HC), abdominal circumference (AC), femur length (FL) and if same coefficients are used, the birth weight prediction for fetuses with altered growth may result in errors. This calls for targeted birth-weight-specific models derived exclusively 
from study of SGA fetuses or low birth weight neonates. ${ }^{4-6}$ The aim of the present study is to test established formulae in fetuses $\leq 2000 \mathrm{gm}$ at birth in correlation with actual birth weight and to develop new formula for this group of fetuses delivering in our institution.

\section{MATERIALS AND METHODS}

This prospective study was done at a tertiary maternal unit of Kasturba Medical College, Manipal over a period of 1 year between 2014 and 2015. This center serves as a referral unit for high-risk pregnancies for surrounding four districts (Dakshina Kannada, Davanagere, Shimoga, Uttara Kannada, Udupi, and Chikmagalur with a $9,540,390$ population). ${ }^{7}$ Prior to the recruitment of subjects, informed consent was taken and Institutional Ethical Committee gave permission to conduct the study. We included only those women who had ultrasound data within 1 week of delivery (total 159 women, formula derivation: 128 , formula validation: 31 ).

Our main inclusion criterion was singleton live pregnancy with actual birth weight of fetus less than 2000 gm. Multiple pregnancies, fetuses with intrauterine death, chromosomal, or structural abnormalities or those who lack complete information regarding biometric parameters were excluded. Gestational age was determined from the last menstrual period and first- or second-trimester biometry. Each fetus was included only once. We used (Philips HD11XE) ultrasound machine to measure biometric parameters. The BPD was measured in transthalamic view, at the level of thalami and cavum septum pellucidum from the outer edge of the skull in the near field to the inner edge of the skull in the far field. The HC was also measured in the transthalamic view by placing an ellipse around the outer edge of the skull. The fetal AC was measured around the outer border of skin at the level of stomach and confluence of umbilical vein with the portal sinus. The FL was measured with the beam right angle to the long axis of shaft, taking care not to include the epiphysis. These parameters (BPD, HC, AC, and FL) are taken within 1 week of delivery and applied in various formulae described and correlated with actual birth weight after delivery. Birth weight was noted within 1 hour of delivery by our nursing staff using electronic balance with minimal error of $5 \mathrm{gm}$.

We considered neonatal birth weight as dependent variable and fetal biometric parameters (BPD, HC, AC, and FL) as independent variables. We calculated sample size using the model $n>50+8 K^{8} ; \mathrm{K}$ indicates number of independent variables, which indicated that minimum of 82 subjects should be included in the formula derivation group. Our sample size was 128 subjects which were more than adequate for statistical derivation.
Table 1: Birth weight formulae used in the present study

\begin{tabular}{ll}
\hline Authors & Birth weight equations \\
\hline Hadlock et al $^{11}$ & Log $(\mathrm{EFW})=1.5662-0.0108(\mathrm{HC})+0.0468(\mathrm{AC})+$ \\
& $0.171(\mathrm{FL})+0.00034(\mathrm{HC}) 2-0.003685(\mathrm{ACXFL})$ \\
Weiner et al $^{12}$ & $\log (\mathrm{EFW})=1.6961+0.02253(\mathrm{HC})+0.01645(\mathrm{AC})+$ \\
& $0.06439(\mathrm{FL})$ \\
Weiner et al $^{12}$ & $\log (\mathrm{EFW})=1.6575+0.04035(\mathrm{HC})+0.01285(\mathrm{AC})$ \\
Scott et al $^{13}$ & $\log (\mathrm{EFW})=0.66 \times \log (\mathrm{HC})+1.04 \times \log (\mathrm{AC})+$ \\
& $0.985 \times \log (\mathrm{FL})$ \\
Schild et al $^{14}$ & $\mathrm{EFW}=5381.193+150.324 \times(\mathrm{HC})+2.069 \times$ \\
& $(\mathrm{FL})^{3}+0.0232 \times(\mathrm{AC})^{3}-6235.478 \times \log (\mathrm{HC})$ \\
\hline
\end{tabular}

AC: Abdominal circumference; BPD: Biparietal diameter; EFW: Estimated fetal weight; FL: Femur length; HC: Head circumference

We used advanced regression software (PHOEBE - a framework of estimating fetus weight and age $)^{9}$ to find the best fit regression formula for these 128 subjects.

This formula was compared with already established ultrasound formulae for errors in fetal weight estimation (Table 1). We calculated mean absolute error and mean absolute percentage error using the following formulae:

- Mean absolute error $=\sum(\mathrm{EFW}-\mathrm{BW}) / \mathrm{n}$

- Mean absolute percentage error $=\Sigma[(E F W-B W) /$ $\mathrm{BW}] / \mathrm{n} \times 100$

We used Bland and Altman ${ }^{10}$ plot (1986) as a measure of detecting significant differences between actual birth weight and predicted birth weight.

Furthermore, we prospectively validated our derived mode in further cohort of 31 fetuses, for its ability to predict birth weight within various ranges from 5 to $20 \%$.

The derived formula and its validity were tested in 31 fetuses further. Error in estimation was calculated according to formulae given below.

\section{RESULTS}

The demographic profiles of our subjects are given in Table 2, separated into formula derivation and validation groups. In both groups, maternal age, gestational age, sex of fetuses, duration of gestation, and weight of fetuses were matched except for parity, though it appeared that formula validation group had slightly more multigravidae (58\%) than in formula derivation group (49.21\%); however, this was not statistically significant.

Computerized analysis using PHOEBE fetal weight software yielded the following formula with good fit and minimal errors.

$\log 10($ Birth Weight $)=1.0131+0.0216 \times \mathrm{HC}+0.0448 \times$ $\mathrm{AC}+0.2183 \times \mathrm{FL}+0.0001 \times \mathrm{BPD} \times \mathrm{AC}-0.0059 \times \mathrm{AC} \times \mathrm{FL}$

This abovementioned formula was compared with the existing formulae and the results are given in Table 3, and the formula was superior to established birth weight 
Table 2: Demographic profile

\begin{tabular}{lll}
\hline & $\begin{array}{l}\text { Formula } \\
\text { derivation } \\
\text { group }(n=128)\end{array}$ & $\begin{array}{l}\text { Formula } \\
\text { validation group } \\
(n=31)\end{array}$ \\
Characteristics & 27.6 years & 27.9 years \\
\hline Maternal age in years & 32.3 weeks & 32 weeks \\
Gestational age at delivery & & \\
in weeks & $50.7 \%$ & $41.9 \%$ \\
Primi & $49.21 \%$ & $58 \%$ \\
Multi & $51.5 \%$ & $51.6 \%$ \\
Female & $48.5 \%$ & $48.4 \%$ \\
Male & $0.8 \%$ & 0 \\
$<24$ weeks & $25 \%$ & $32.2 \%$ \\
$24-30$ weeks & $74.2 \%$ & $67.7 \%$ \\
$>30$ weeks & 0 & $3.2 \%$ \\
$<500$ gm & $19.5 \%$ & $29 \%$ \\
$500-1000$ gm & $80.5 \%$ & $67.7 \%$ \\
$>1000$ gm & $1424.4 \mathrm{gm}$ & $1337 \mathrm{gm}$ \\
Estimated fetal weight & $1403 \mathrm{gm} \pm 398$ & $1328 \mathrm{gm} \pm 454$ \\
Actual birth weight & &
\end{tabular}

Table 3: Mean birth weight in grams by various formulae in the formula derivation group $(n=128)$

\begin{tabular}{ll}
\hline Method & $\begin{array}{l}\text { Estimated birth } \\
\text { weight }(\text { Mean } \pm S D)^{*}\end{array}$ \\
\hline Hadlock et al $^{11}$ & $1399 \pm 405$ \\
Weiner et al $^{12}$ & $1254 \pm 350$ \\
Weiner et al $^{12}$ & $1239 \pm 330$ \\
Scott et al $^{13}$ & $1392 \pm 356$ \\
Schild et al & \\
New formula & $1287 \pm 326$ \\
\hline
\end{tabular}

${ }^{*}$ Actual birth weight $=1403 \pm 398$

formulae. The mean birth weight obtained using this formula was closest to actual birth weight (Table 3).

The lowest mean \pm SD absolute error was $130 \pm 91 \mathrm{gm}$ and the lowest mean absolute percentage error was $9.8 \pm$ $7 \%$ SD (Table 4 ). With the new formula, $34.4 \%$ of estimates fell within $\pm 5 \%$ of the actual weight at birth, $61.7 \%$ fell within $\pm 10 \%, 83.6 \%$ fell within $\pm 15 \%$, and $91.4 \%$ fell within $\pm 20 \%$ (Table 5) in the formula derivation group.

When this formula was applied in the validation group, the mean \pm SD of estimated birth weight was $1337 \pm$ $406 \mathrm{gm}$, which was closest to actual birth weight in grams $(1328 \pm 433)$ and the absolute error in grams was $102 \pm$ 115 and absolute percentage error was $7.4 \pm 7.2$ (Table 6). In the validation group, $67.7 \%$ fell within $5 \%, 77.4 \%$ fell within $10 \%, 80.6 \%$ fell within $15 \%, 90.3 \%$ fell within $20 \%$.

From Table 3, among various formulae tested in estimating fetal weight, weight estimated by Hadlock formula was closest to actual birth weight and the next best one was Scott estimation (mean $\pm \mathrm{SD}$ ). Formula derived by us was much better than other formulae.

Table 4 shows that absolute error and absolute percentage error in estimating fetal weight were lowest with Scott formula followed by Hadlock formula among
Table 4: Estimate of errors in birth weight calculation using different equations (formula derivation group, $n=128$ )

\begin{tabular}{|c|c|c|}
\hline Method & $\begin{array}{l}\text { Absolute } \\
\text { error in grams } \\
\text { (Mean } \pm S D \text { ) }\end{array}$ & $\begin{array}{l}\text { Absolute } \\
\text { percentage error } \\
(\text { Mean } \pm S D)\end{array}$ \\
\hline Hadlock et al ${ }^{11}$ & $142 \pm 118$ & $10.4 \pm 8$ \\
\hline Weiner et al ${ }^{12}$ & $173 \pm 145$ & $11.9 \pm 8.5$ \\
\hline Weiner et al ${ }^{12}$ & $197 \pm 157$ & $13.4 \pm 9.4$ \\
\hline Scott et al ${ }^{13}$ & $132 \pm 107$ & $10 \pm 8.1$ \\
\hline Schild et al ${ }^{14}$ & $152 \pm 134$ & $10.4 \pm 8$ \\
\hline New formula & $130 \pm 91$ & $9.8 \pm 7$ \\
\hline
\end{tabular}

Table 5: Percentage of cases within actual birth weight $(n=128)$

\begin{tabular}{|c|c|c|c|c|}
\hline Formula & $\pm 5 \%$ & $\pm 10 \%$ & $\pm 15 \%$ & $\pm 20 \%$ \\
\hline Hadlock et al ${ }^{11}$ & 32.6 & 57.8 & 75.8 & 90.6 \\
\hline Weiner et al ${ }^{12}$ & 25 & 51.6 & 71.1 & 82.8 \\
\hline Weiner et $\mathrm{al}^{12}$ & 23.4 & 47.7 & 64.1 & 76.6 \\
\hline Scott et al ${ }^{13}$ & 33.6 & 61.7 & 80.5 & 88.3 \\
\hline Schild et $\mathrm{al}^{14}$ & 40.6 & 56.3 & 71.9 & 88.3 \\
\hline New formula & 34.4 & 61.7 & 83.6 & 91.4 \\
\hline
\end{tabular}

Table 6: New formula validation statistics $(n=31)$

\begin{tabular}{ll}
\hline Estimated birth weight (mean \pm SD) & $1337 \pm 406$ \\
Actual birth weight (mean \pm SD) & $1328 \pm 433$ \\
Absolute error in gm (mean \pm SD) & $102 \pm 115$ \\
Absolute percentage error (mean \pm SD) & $7.4 \pm 7.2$ \\
Ability to predict birth weight within 5,10, & $67.7,77.4,80.6$, \\
$15,20 \%$ & $90.3 \%$ respectively \\
\hline
\end{tabular}

established formulae. Our formula stands best among all formulae.

Table 5 demonstrates percentage of cases in whom fetal weight estimated was within $5 \%$ of actual birth weight by Schild was better but after that Scott formula performed better within 10,15, 20\% compared with other established formulae. Our formula was slightly better among all formulae.

Table 6 formula (new), which was derived when validated prospectively in 31 cases, shows us that estimated mean birth weight was closest to actual birth weight and error in estimating fetal weight was low and it includes 77.4 and $80.6 \%$ of cases within 10 and $15 \%$ of actual birth weight range respectively.

New formula performed better in both prevalidation and validation phases and hence was a measure of accurate estimation of fetal birth weight.

We used Bland and Altman ${ }^{10}$ plot (1986) as a measure of detecting significant differences between actual birth weight and predicted birth weight. In this method of comparison, the $X$ axis indicates actual birth weight range and $\mathrm{Y}$ axis indicates birth weight differences between estimated and actual birth weight for that particular birth weight. The value 0 in $\mathrm{Y}$ axis indicates no difference. Excess estimations are indicated as positive graphs and 
underestimations as negative graphs. These differences are shown in $\mathrm{Y}$ axis incrementally.

The scattered diagram shows all the subjects in the group and also mean of the differences of estimates $+2 \mathrm{SD}$ above the mean and $-2 \mathrm{SD}$ below the mean which are shown as horizontal colored lines. In ideal and perfect model fit, mean line should be close to zero and so as the other two lines. If mean is above zero, it indicates excess estimation than the actual birth weight and below zero, it indicates underestimation. If distance between +2SD and -2SD lines is wide apart, large error in weight estimation is likely to exist.

We have drawn Bland Altman plots for birth weights estimated by all five existing birth weight formulae and our formula.

Graph 1 illustrates that mean birth weight estimated by Hadlock formula was closest to actual birth weight and error in estimation was low as dispersion between two colored lines was low.

Graph 2 depicts us that mean birth weight estimated by Weiner et $\mathrm{al}^{12}$ was in negative range and it underestimates

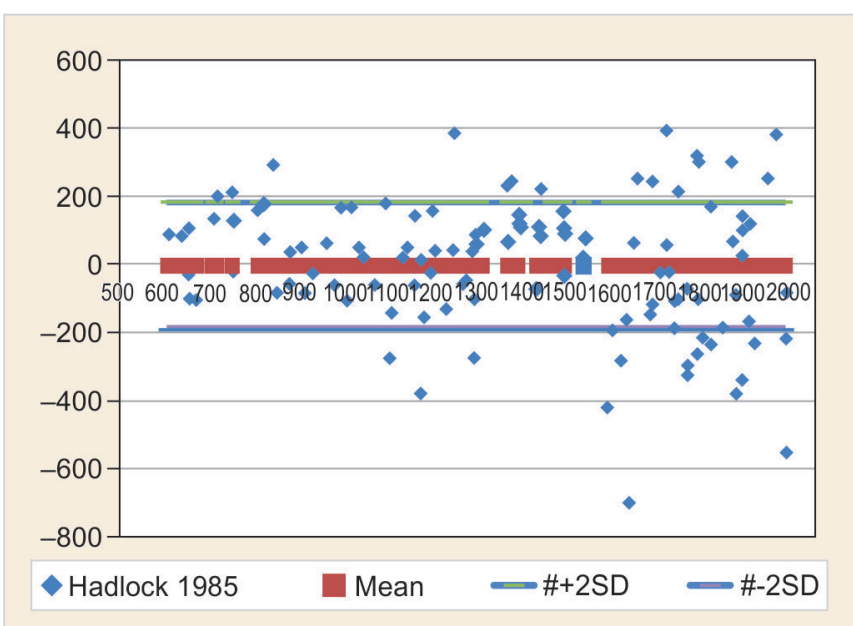

Graph 1: Bland-Altman plot for birth weight estimation by Hadlock ${ }^{11}$ et al method

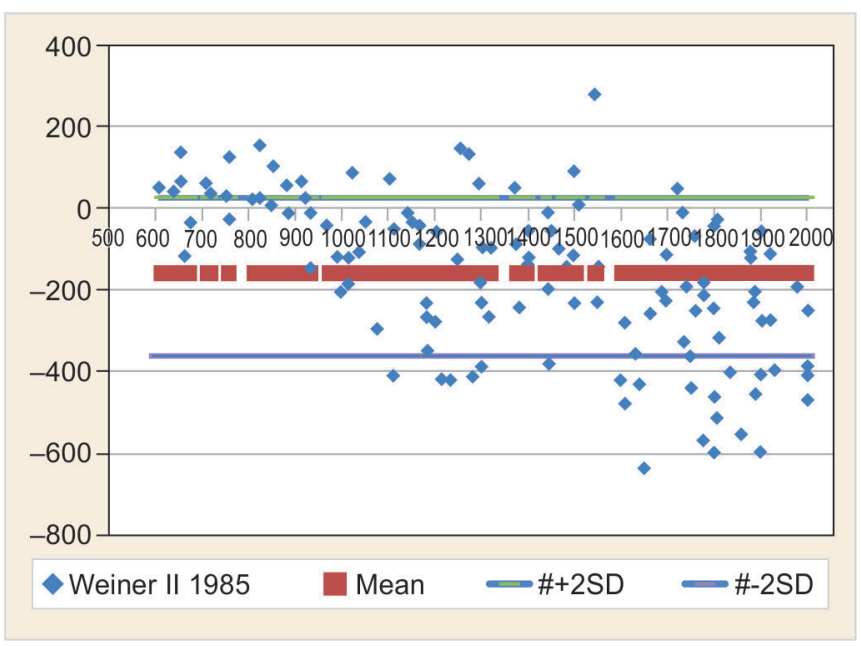

Graph 3: Bland-Altman plot for birth weight estimation by Weiner II et al ${ }^{12}$ method birth weight and error in estimating birth weight was more as the dispersion between the two colored lines was more.

Graph 3 depicts us that mean birth weight estimated by Weiner et $\mathrm{al}^{12}$ was in negative range and it underestimates birth weight and error in estimating birth weight was more as the dispersion between the two colored lines was more.

Graph 4 shows us that mean birth weight estimated by Scott formula was closest to actual birth weight and error in estimation was low as the dispersion was less.

Graph 5 depicts us that mean birth weight estimated by Schild formula was in negative range and it underestimates birth weight and error in estimation was more as the dispersion was more.

From the above graphs (Graph 6) we conclude that Hadlock and Scott formula estimations were better in estimating fetal weight in low birth weight babies among established formulae and our formula was the best among all formulae.

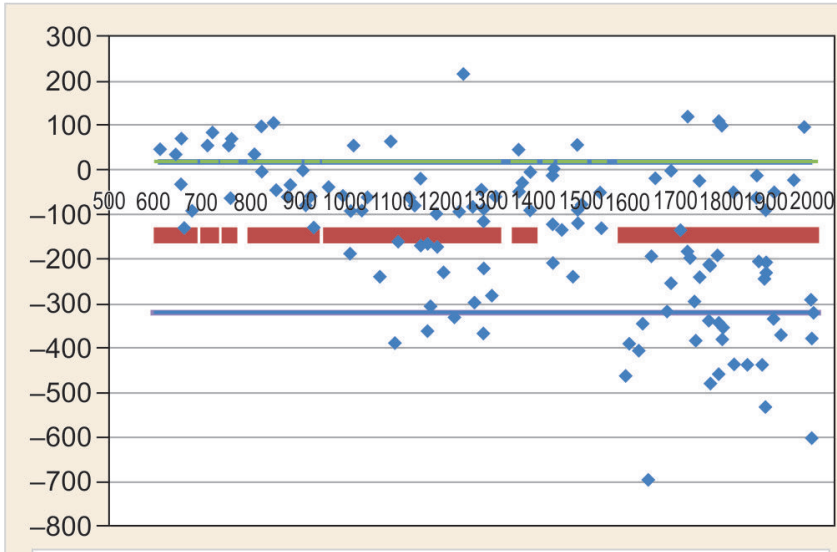

$\rightarrow$ Weiner I 1985 Mean —\#+2SD —-2SD

Graph 2: Bland-Altman plot for birth weight estimation by Weiner et $\mathrm{al}^{12}$ method

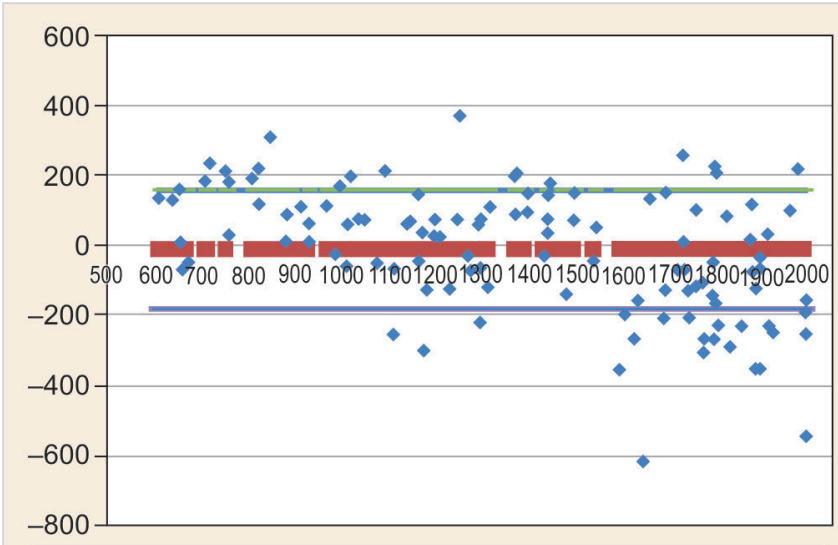

$\checkmark$ Scott $1996 \quad$ Mean $\quad$ \#+2SD \#-2SD

Graph 4: Bland-Altman plot for birth weight estimation by Scott et al $^{13}$ method 


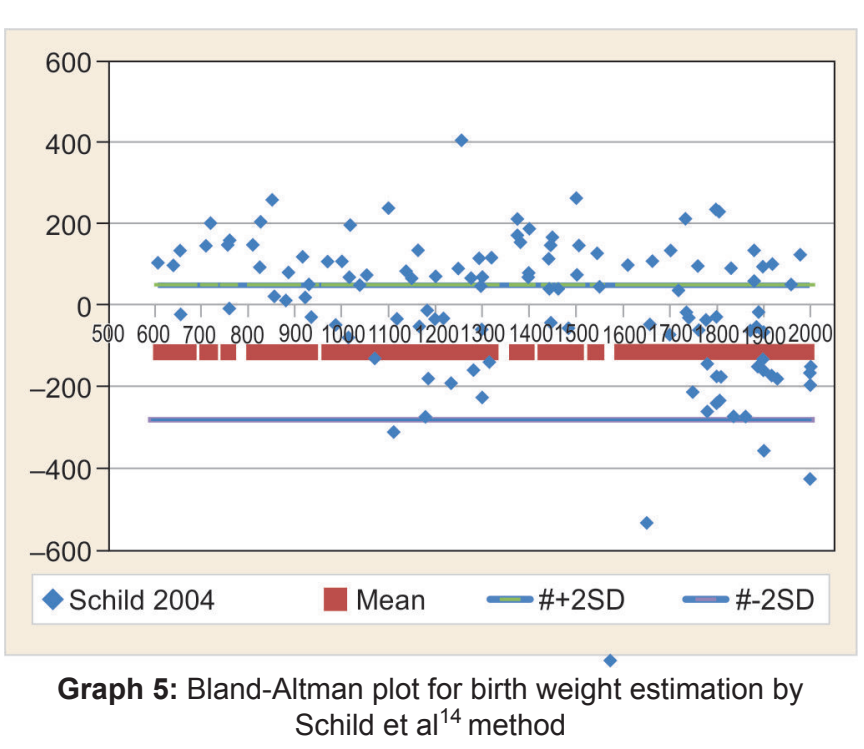

\section{DISCUSSION}

Birth weight is the principal and probably the singlemost factor affecting perinatal morbidity, especially in the small fetus. The obstetrician involved in the labor management of pregnant women with small babies should be aware of the size of the baby as this greatly determines the route of delivery and helps obstetrician to counsel the parents regarding the neonatal survival. The established formulae were derived from ultrasound examination of fetuses close to term and were designed 20 years ago. Special attention was not given to birth of extremely small neonates as in those days their survival was questionable. Majority of such fetuses were delivered vaginally and they succumbed either during labor or in early neonatal period. However, in the present era, the neonatal intensive care facilities have improved a lot and there is good survival rates for even babies weighing as small as $800 \mathrm{gm}$. So the estimation of fetal weight with the established formulae in the preterm fetus might not be precise and there is a need for dedicated birth weight prediction models for this subset of neonates.

It is well known that head to trunk ratio declines as fetus approaches term. A study ${ }^{15}$ showed that the mean $\mathrm{HC} / \mathrm{AC}$ ratio was 1.18 at 17 weeks, but declined to 1.11 till 29 weeks. A further decline in ratio to 1.01 at 36 weeks and 0.96 at 40 weeks was noted. Thus current fetal weight estimation formulae address term babies and may not be applicable for small babies which have a different head to trunk ratios.

Anderson et $\mathrm{al}^{16}$ concluded in their study that a major source of error is due to equation per se, and especially if the birth weight was $<1000 \mathrm{gm}$, there was greater bias and poorer precision. The Hadlock formula, i.e., most commonly used was also tested in smaller babies. It underestimated actual weight by 10 to $14 \%$ with a SD of 37 to $50 \%$, which is not acceptable in making clinical decision in management.

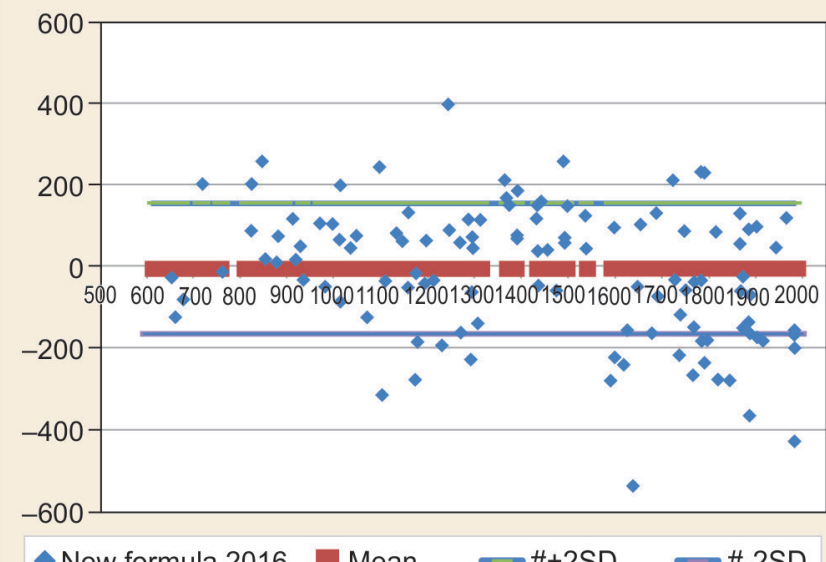

$\checkmark$ New formula 2016 Mean $\quad$ \#+2SD \#-2SD

Graph 6: Bland-Altman plot for birth weight estimation by new formula

A few birth weight formulae were developed for the preterm fetuses. These formulae may improve weight estimation by taking into account the altered headtrunk ratio and the growth restriction found in them. Weinberger et $\mathrm{al}^{17}$ developed a formula using BPD, AC on 41 fetuses with weight between 500 and 2000 gm whose ultrasound parameters were available within 48 hours of delivery [10.1 (AC $\times$ BPD in $\mathrm{cm})-481$ ] and compared with four existing equations. They concluded that derived formula was easy to use and $36.6 \%$ birth weights fell within 5,78 within 10 , and $95.1 \%$ within $20 \%$ of actual birth weight. However, prospective validity of new formula was not tested.

In a retrospective study, Weiner et $\mathrm{al}^{12}$ designed a formula for estimating weight in preterm fetus, including $\mathrm{HC}, \mathrm{AC}$, and FL measurements. Predictive accuracy of established formulae in 69 preterm fetuses who delivered within 48 hours of delivery of scan was examined. The mean birth weight was $1396 \mathrm{gm}$. They concluded that the use of $\mathrm{HC}$ and FL in preterm fetuses strengthens the formula in estimating fetal weight.

Thurnau et $\mathrm{al}^{18}$ did a study whose objective was to establish a formula which is simple, user-friendly, and accurate, when used in small fetuses $(<2500 \mathrm{gm})$. Ultrasound parameters were noted within 7 days of delivery. Mean gestational age was 28.5 weeks and mean birth weight in this study was $1135 \mathrm{gm}$. The following formula was derived using BPD, $\mathrm{HC}$ as the parameters $[E F W=(B P D \times A C \times 9.337)-229]$. When compared with actual birth weight, correlation coefficient (R) was 0.957 . The derived formula was applied prospectively and demonstrated best results.

Sabbagha et $\mathrm{al}^{4}$ tested various established formulae on large, appropriate, and small for gestational age fetuses in both preterm and term on 575 singleton pregnancies in whom scan parameters were available within 1 week of delivery. Three formulae were generated for three 
groups based on the following: Gestational age (weeks) + head circumference $(\mathrm{cm})+2 \times$ abdominal circumference $(\mathrm{cm})+$ femur length $(\mathrm{cm})$. They compared with Hadlock and Weiner formulae and found that absolute error and absolute percentage error were less with developed formulae in respective three groups.

Scott et al $^{13}$ performed a study on 142 fetuses with a weight of less than $1000 \mathrm{gm}$ who delivered within 1 week of scan. They established a new formula which included HC, AC, and FL as parameters and prospectively validated on 27 fetuses with a birth weight in a range of 420 to $1080 \mathrm{gm}$. The Scott formula was more accurate than other established formulae with which it was compared. Among the various formulae available, Hadlock formula was more accurate. Similar results were found in our study.

Schild et $\mathrm{al}^{14}$ developed and prospectively tested a formula in 2004 in a group of fetuses $\leq 1600 \mathrm{gm}$. It had the mean absolute error $(66.2 \pm 59 \mathrm{gm})$ and the mean absolute percentage error $(7.1 \pm 5.9 \%)$. Of all, $48.3 \%$ fell within $5 \%$ of the birth weight, $73.6 \%$ within $10 \%, 90.8 \%$ within $15 \%$, and $95.4 \%$ within $20 \%$.

Melamed et $\mathrm{al}^{6}$ conducted a study on 370 women who delivered a small of gestational age baby and whose scan parameters were available within 1 week of delivery. Various established formulae in estimating fetal weight were tested in whole cohort and in specific subgroups like early and late SGA. They concluded that these formulae have significant errors when used in whole cohort together and their accuracy improved when they are applied to specific subgroups individually and Scott model was the best among available formulae.

In our study, we tested the already established and most commonly used formulae on 128 preterm fetuses and found that Hadlock and Scott formulae were still the best and we generated a new formula $(\log 10(\mathrm{BW})=1.0131+$ $0.0216 \times \mathrm{HC}+0.0448 \times \mathrm{AC}+0.2183 \times \mathrm{FL}+0.0001 \times \mathrm{BPD} \times$ $\mathrm{AC}-0.0059 \times \mathrm{AC} \times \mathrm{FL}$ ) that was superior to already available formulae. The mean birth weight obtained was closest to actual birth weight (Table 3). It has the lowest mean \pm SD absolute error $(130 \pm 91 \mathrm{gm})$ and the lowest mean absolute percentage error $(9.8 \pm 7 \%$ SD) (Table 4$)$. With the new formula, $34.4 \%$ of estimates fell within $\pm 5 \%$ of the actual weight at birth, $61.7 \%$ fell within $\pm 10 \%$, $83.6 \%$ fell within $\pm 15 \%$, and $91.4 \%$ fell within $\pm 20 \%$ (Table 5) in the formula derivation group. When this formula was applied in the validation group, the mean \pm SD of estimated birth weight was $1337 \pm 406$ gm, which was closest to actual birth weight in grams $(1328 \pm 433)$ and the absolute error in grams was $102 \pm 115$ and absolute percentage error was $7.4 \pm 7.2$ (Table 6). In the validation group, $67.7 \%$ fell within 5\%, 77.4\% fell within 10\%, $80.6 \%$ fell within 15\%, and $90.3 \%$ fell within $20 \%$. Hereby we conclude that among various available formulae, Hadlock and Scott formulae holds good even for estimation of weight in fetuses $\leq 2000 \mathrm{gm}$ at birth. In comparison to available formulae, absolute error and absolute percentage error in estimating fetal weight $(\leq 2000 \mathrm{gm})$ are least, with our formula indicating a good fit (Graphs 1 to 6).

\section{LIMITATIONS}

Though the sample size meets requirement for regression analysis to derive birth weight, better regression coefficients may be derived if tested on even larger sample size. The study period was for 1 year duration and after deriving the formula by studying 128 newborns, we could only prospectively validate the formula on next 31 babies. The validation results would have been still robust if we could enroll more number of subjects by extending the study period. Anyhow, we have demonstrated how the study could be planned and regression analysis can be carried out with ease, so that we can establish our own standard formulae suitable for our population, instead of depending on western birth weight estimation formulae.

\section{REFERENCES}

1. Simon NV, Levisky JS, Shearer DM, O'Lear MS, Flood JT. Influence of fetal growth patterns on sonographic estimation of fetal weight. J Clin Ultrasound 1987 Jul-Aug;15(6):376-383.

2. Stefanelli S, Groom KM. The accuracy of ultrasound-estimated fetal weight in extremely preterm infants: a comparison of small for gestational age and appropriate for gestational age. Aust N Z J Obstet Gynaecol 2014 Apr;54(2):126-131.

3. Larciprete G, Valensise H, Di Pierro G, Vasapollo B, Casalino B, Arduini D, Jarvis S, Cirese E. Intrauterine growth restriction and fetal body composition. Ultrasound Obstet Gynecol 2005 Sep;26(3):258-262.

4. Sabbagha RE, Minogue J, Tamura RK, Hungerford SA. Estimation of birth weight by use of ultrasonographic formulas targeted to large-, appropriate-, and small-for-gestational-age fetuses. Am J Obstet Gynecol 1989 Apr;160(4):854-860.

5. Souka AP, Papastefanou I, Michalitsi V, Pilalis A, Kassanos D. Specific formulas improve the estimation of fetal weight by ultrasound scan. J Matern Fetal Neonatal Med 2014 May;27(7):737-742.

6. Melamed N, Ryan G, Windrim R, Toi A, Kingdom J. Choice of formula and accuracy of fetal weight estimation in small-forgestational-age fetuses. J Ultrasound Med 2016 Jan;35(1):71-82.

7. Population Census 2011. Karnataka State District Wise Census [last cited 2015 Mar 21]; 2011. Available from: http:/ / www. census2011.co.in/census/state/districtlist/ karnataka.html.

8. Green SB. How many subjects does it take to do a regression analysis. Multivariate Behav Res 1991 Jul 1;26(3):499-510.

9. Phoebe-A framework of estimating fetus weight and age; 2013. Available from: https://sites.google.com/site/ngphloc/st/ products/phoebe.

10. Bland JM, Altman DG. Statistical methods for assessing agreement between two methods of clinical measurement. Lancet 1986 Feb 8;1(8476):307-310. 
11. Hadlock FP, Harrist RB, Sharman RS, Deter RL, Park SK. Estimation of fetal weight with the use of head, body, and femur measurements - a prospective study. Am J Obstet Gynecol 1985 Feb 1;151(3):333-337.

12. Weiner $\mathrm{CP}$, Sabbagha RE, Vaisrub N, Socol ML. Ultrasonic fetal weight prediction: role of head circumference and femur length. Obstet Gynecol 1985 Jun;65(6):812-817.

13. Scott F, Beeby P, Abbott J, Edelman D, Boogert A. New formula for estimating fetal weight below $1000 \mathrm{gm}$ : comparison with existing formulas. J Ultrasound Med 1996 Oct;15(10):669-672.

14. Schild RL, Fell K, Fimmers R, Gembruch U, Hansmann M. A new formula for calculating weight in the fetus of $<$ or $=1600 \mathrm{gm}$. Ultrasound Obstet Gynecol 2004 Dec;24(7):775-780.

15. Tongsong T, Wanapirak C, Takapijitra A. Ultrasonic measurement of the fetal head to abdominal circumference ratio in normal pregnancy. J Med Assoc Thai 1993 Mar;76(3): 153-158.

16. Anderson NG, Jolley IJ, Wells JE. Sonographic estimation of fetal weight: comparison of bias, precision and consistency using 12 different formulae. Ultrasound Obstet Gynecol 2007 Aug;30(2):173-179.

17. Weinberger E, Cyr DR, Hirsch JH, Richardson T, Hanson JA, Mack LA. Estimating fetal weights less than $2000 \mathrm{gm}$ : an accurate and simple method. AJR Am J Roentgenol 1984 May;142(5):973-977.

18. Thurnau GR, Tamura RK, Sabbagha R, Depp OR III, Dyer A, Larkin R, Lee T, Laughlin C. A simple estimated fetal weight equation based on real-time ultrasound measurements of fetuses less than thirty-four weeks' gestation. Am J Obstet Gynecol 1983 Mar 1;145(5):557-561. 